\title{
A EXCEÇÃO É A REGRA: OS CENTROS DE DETENÇÃO PARA IMIGRANTES NA ITÁLIA
}

\author{
Fernanda Di Flora Garcia*
}

\begin{abstract}
No início dos anos 1990, diante do aumento exponencial dos fluxos migratórios, a Itália proclama o Estado de emergência para lidar com o fenômeno, adotando leis cada vez mais restritivas de ingresso e permanência no país e edificando espaços de exceção para confinar imigrantes irregulares, refugiados e solicitantes de asilo. Após quase 20 anos, o Estado de emergência continua em vigor e os centros de detenção ${ }^{1}$ se multiplicam diante dos acontecimentos decorrentes da Primavera Árabe. O objetivo deste artigo é analisar como as medidas excepcionais tornaram-se a regra na Itália e qual o impacto da existência destes espaços de exceção para a convivência civil.
\end{abstract}

Palavras-chave: centros de detenção para imigrantes, Estado de exceção, racismo, Itália.

\section{Introdução}

Na madrugada de sete de março de 1991, milhares de refugiados albaneses desembarcaram no litoral italiano, na cidade portuária de Bari, após a queda do regime comunista no país. Ao longo de poucos dias, 27 mil albaneses ingressaram em uma cidade de 90 mil habitantes, enquanto o governo italiano articulava uma campanha contra o "tsunami humano"2, concluindo com a proclamação do "Estado de emergência humanitário", que tem sido reiteradamente acionado desde então. Logo após o desembarque, os albaneses foram rapidamente detidos e confinados no estádio de futebol da cidade, onde permaneceram durante semanas

* Doutoranda em Sociologia pela Universidade Estadual de Campinas. Piracicaba - SP/Brasil.

1 Esse trabalho baseia-se na dissertação: GARCIA, Fernanda Di Flora. "Sobre os centros de permanência temporária na Itália e a construção social da não-pessoa". Campinas, 2011, 201p. Dissertação de Mestrado-Instituto de Filosofia e Ciências Humanas, Universidade Estadual de Campinas-UNICAMP.

2 Cf. DAL LAGO, Alessandro. Non-persone. L'esclusione dei migranti in una società globale; RIVERA, Annamaria. Due anni di scena razzista in Italia. Protagonisti e comprimari, vittime e ribelli. 
até serem repatriados para a Albânia, a despeito do potencial reconhecimento de seu status jurídico de refugiados. Esse é o evento emblemático que marca a nova orientação política italiana no que se refere aos temas imigração, refúgio e asilo, em consonância com os princípios considerados como fundamentais pela União Europeia no combate ao fluxo massivo de pessoas em seu interior, entre os quais destacam-se a militarização das fronteiras, a detenção administrativa e leis de imigração cada vez mais repressivas, punitivas e de amplo caráter discriminatório. O confinamento dos albaneses no estádio de Bari foi a primeira experiência de detenção e confinamento de potenciais refugiados, imigrantes e solicitantes de asilo, marcando o início do processo de edificação de centros de detenção como medida eficaz para lidar com o aumento exponencial dos fluxos migratórios e transformando medidas de caráter emergencial em normas regulares, independentemente da existência real de uma situação excepcional.

\section{A declaração da emergência: contexto histórico e político}

No início da década de 1990, após a queda do comunismo, da dissolução do bloco soviético e do avanço do fenômeno da globalização, diversos países europeus passaram a receber um fluxo intenso de imigrantes em seu território, oriundos das mais diversas partes do globo. Entre estes países, destacaram-se Itália, Espanha e Grécia, que foram definidos como países de "nova imigração", por tratar-se de países de tradição emigratória que receberam fluxos migratórios em dimensões e escalas sem precedentes. Estes países passaram a cumprir o papel de "sentinelas" da União Europeia, guardando suas fronteiras e seguindo as políticas migratórias orientadas pelo bloco ${ }^{3}$ no sentido de dificultar o acesso e a permanência em seu interior, sobretudo dos imigrantes irregulares, refugiados e solicitantes de asilo ${ }^{4}$. No caso italiano, a campanha contra o "perigo albanês" foi o dispositivo mobilizado para legitimar a adoção da ideologia da segurança e para a difusão do clima de pânico, do qual se beneficiaram os partidos e movimentos sociais de direita, especialmente a Liga Norte.

O caso italiano é exemplar porque evidencia a maneira pela qual os discursos políticos e midiáticos verteram-se em medidas governamentais

\footnotetext{
3 Importante observar que a postura liberal italiana no que diz respeito às suas fronteiras foi vista como um impedimento para a integração do país no acordo de Schengen. Apesar de ter assinado formalmente o acordo em 1990, sua integração total ao sistema se efetivou somente em 1998, quando a política migratória italiana passou a ser considerada como compatível com os pressupostos da União Européia, ou seja, quando foram estabelecidas restrições mais severas para regulamentar o ingresso e a permanência no país e quando foram estabelecidos os centros de detenção para os estrangeiros em situação irregular.

4 Exemplar, nesse sentido, é a restrição do direito ao refúgio e asilo ocorrida na Alemanha na década de 1990. Ver especialmente "Imigração, cidadania e identidade nacional" de Jurgen Habermas in A inclusão do outro: estudos de teoria política. São Paulo: Loyola, 2002.
} 
securitárias amplamente aceitas em um curto espaço de tempo, de maneira que o próprio discurso sobre um determinado fenômeno social - assim como sua ampla difusão - mostra-se capaz de alterar a cultura, as práticas cotidianas. A ótica securitária conjugada à retórica do perigo serviram para justificar a adoção de medidas excepcionais que excedem o quadro jurídico regular, colocando a emergência e a segurança nacional em um lugar de destaque na práticas governamentais e estratégias midiáticas bem como na vida do cidadão comum e nas suas relações com os estrangeiros. Se até os anos 1980 a convivência com os estrangeiros era considerada pacífica ou isenta de violência simbólica e material, no espaço de poucos anos essa postura dá lugar à hostilidade e a eventos cotidianos de violência contra os imigrantes 5 .

Com efeito, o governo italiano, até o início dos anos 1980, caracterizava-se tanto por uma postura de indiferença institucional com relação aos estrangeiros quanto por uma prática de abertura de fronteiras. Com o objetivo de fomentar o turismo, a Itália era considerada "liberal" ${ }^{6} \mathrm{com}$ relação ao ingresso, permanência e saída do país bem como no tratamento destinado aos imigrantes e refugiados. Até este período, não havia uma legislação específica que regulamentasse os dispositivos a serem utilizados na gestão da migração, as mudanças legislativas ocorridas até então versavam principalmente sobre a incorporação dos tratados internacionais dos quais o país era signatário e que visavam proteger seus emigrantes. Embora tenha ocorrido um aumento substancial no ingresso de imigrantes na Itália no início dos anos 1980, a postura do Estado com relação a esses fluxos foi marcada novamente pela ambiguidade, tratando tais fluxos ora com indiferença, ora de modo positivo a partir de regularizações, como demonstram as alterações jurídicas deste período ${ }^{7}$.

Enquanto o Estado italiano e suas instituições mostravam-se, de modo geral, indiferentes ao ingresso e permanência de migrantes em seu território ${ }^{8}$, os países membros da União Europeia e os Estados Unidos apresentavam-se como

5 Muitas cidades italianas, especialmente aquelas situadas no norte do país, organizaram comitês de cidadãos cujo objetivo principal era a mobilização contra os ambulantes de origem estrangeira e a própria presença dos imigrantes. As "rondas" de cidadãos foram institucionalizadas em 2009, no governo Berlusconi, com o Pacto de Segurança.

6 Cf. BROCHAMAMN, Grete; HAMMAR, Tomas. Planning in the dark: the evolution of Italian Immigration Control.

7 O primeiro programa de regularização dos imigrantes que não possuíam documentos ocorreu em 1982; em 1986 foi feita a primeira lei em matéria de imigração que pretendia garantir aos trabalhadores estrangeiros os mesmos direitos dos cidadãos italianos.

8 Um exemplo da postura "liberal" da Itália pode ser observado na ausência de requerimento, até o ano de 1985, do visto de turista para cidadãos oriundos de 78 países, entre os quais Marrocos, Algéria, Tunísia, Senegal e Mauritânia. Pouco tempo depois, o requerimento dos vistos passou a ser o principal instrumento da política migratória italiana e foi introduzido para todos os países até então liberados de sua apresentação, especialmente os países africanos. 
receptivos e prontos a acolher estes fluxos, especialmente aqueles oriundos dos países que faziam parte do bloco comunista. Acolher estes indivíduos significava também a possibilidade de afirmarem-se como espaços da liberdade e, no limite, como vitoriosos no embate contra a "ditadura" comunista. No entanto, se até esse momento os fluxos migratórios provenientes do leste europeu eram recebidos sem muitas restrições, o quadro mudou radicalmente com a queda do Muro de Berlim e a desagregação do bloco soviético, tanto no cenário geral do continente europeu, quanto específico, como o ocorrido no território italiano. Com a queda do governo comunista da Albânia e devido à ligação histórica entre este país e a Itália, houve um movimento migratório significativo em direção à península itálica, um movimento que fora inicialmente apoiado pelas autoridades italianas e pela opinião pública local. Mas no momento em que o fluxo se intensificou e no período de poucos dias se configurou uma entrada massiva de albaneses, o discurso político sobre a imigração albanesa e a imigração em geral assumiu outra conotação, identificando, primeiramente, os albaneses como criminosos, como responsáveis pelo aumento da delinquência no país e, posteriormente, ampliando tal concepção a todos os indivíduos estrangeiros oriundos do leste europeu, da África, da Ásia e da América Latina. Em um intervalo de tempo de poucos meses, não se falava mais em refugiados mas sim em imigrantes "ilegais" ou "clandestinos" para definir e caracterizar os indivíduos que entraram recentemente no país, em especial os albaneses, cujas demandas por refúgio e asilo passaram a ser arbitrariamente consideradas ilegítimas.

Além do discurso político que passou a caracterizar a presença destes indivíduos como um "risco" à segurança nacional, os meios de comunicação de massa ajudaram a fomentar e a difundir o pânico com relação a uma possível "invasão" estrangeira, impulsionando o medo e transformando os estrangeiros, sejam eles imigrantes, refugiados ou solicitantes de asilo, em potenciais criminosos e colocando a segurança como paradigma fundamental sobre o qual se edificaram as políticas governamentais. A partir do início dos anos 1990, a mídia nacional italiana passou a veicular uma visão estigmatizada e estigmatizante dos imigrantes, produzindo uma imagem da migração profundamente marcada pelo preconceito, pelo racismo e pela xenofobia, fazendo amplo uso de uma linguagem que despersonaliza os estrangeiros, deixando de nomear os indivíduos sobre os quais os acontecimentos narrados se referem e definindo-os por sua nacionalidade, etnia, crença religiosa ou configuração somática ${ }^{9}$. Em suas pesquisas sobre a mídia italiana na sua relação

9 Em relatório efetuado em 2001 pela organização internacional Human Rights Watch, intitulado "Everyday intolerance. Racist and xenophobic violence in Italy", podemos encontrar um catálogo de casos que ilustram a abordagem midiática sobre imigração. O caso de um casal cigano detido em 2008 sob suspeita do sequestro de uma criança de três anos ilustra de modo exemplar tal 
com a alteração da linguagem relacionada à imigração, Marcelo Maneri ${ }^{10}$ destaca como determinadas palavras passaram a acompanhar constantemente as notícias relacionadas aos estrangeiros, marcando negativamente sua presença no interior do país. Um exemplo bastante significativo encontra-se na utilização rotineira da palavra "degradação" que, de acordo com o autor, nos anos compreendidos entre 1995-1997 passou a significar a deterioração da paisagem urbana devido à presença dos imigrantes, dependentes químicos, pequenos delinquentes e que somente no periódico Corriere della Sera aparece em uma média de 53 artigos por ano entre 1998 e 2000. No que toca às narrativas televisivas, em estudo conduzido pela Università Sapienza di Roma, durante a primeira metade de 2008, apenas 26 das 5.684 histórias televisivas sobre os imigrantes não os relacionaram ao crime ou a problemas de segurança ${ }^{11}$.

De acordo com Hanretty e Hermanin"12, o termo "marocchino", por exemplo, é utilizado pelos italianos, tanto no discurso midiático, quanto no discurso popular, como "uma espécie de abreviatura racial para representar todos os imigrantes de cor, sem levar em consideração o local de onde eles são naturais", de modo que em 2005 a Suprema Corte Italiana teve de julgar as circunstâncias e ocasiões nas quais chamar alguém de "marocchino" poderia ser considerado uma ofensa, concluindo que a utilização deste termo e outros que se referem diretamente à origem étnica de um indivíduo, enfatizando-a, constitui uma injúria claramente associada com uma intenção discriminatória. A despeito de tal decisão, tais termos continuam sendo amplamente utilizados no país.

Estas novas práticas discursivas e governamentais ajudaram a edificar a nova política migratória italiana, que evoluiu rapidamente desde então, caracterizando-se por alterações legislativas constantes, que modificaram significativamente o cenário das relações sociais no país com relação ao tratamento destinado aos estrangeiros, que passaram a ser vistos e percebidos como um risco em potencial. A década de 1990 é significativa e fundamental para compreender a política de repressão e criminalização dos imigrantes ainda em curso, porque marca, de acordo com Alessandro Dal Lago, o início de uma prática governamental no interior da qual os imigrantes "encontraram no cárcere

tendência a não nomear os estrangeiros, enfatizando sua origem nacional, étnica, racial. Os maiores jornais italianos narraram o episódio em suas páginas da seguinte maneira: "Dois nômades presos. Eles queriam sequestrar uma menina" (Corriere della Sera); "Cigano tenta sequestrar uma menina arrastando para longe da mãe" (Il Giornale); "Não há dúvida de que foi tentativa de sequestro" (La Stampa). Após quatro meses de detenção provisória, o casal foi absolvido. Apenas um grande jornal (ll Giornale), narrou o fato.

10 MANERI, Marcello. Il panico morale come dispositivo di trasformazione dell'insicurezza.

${ }^{11}$ Cf. HUMAN RIGHTS WATCH. Everyday intolerance. Racist and xenophobic violence in Italy.

${ }^{12}$ HANRETTY, Chris; HERMANIN, Costanza. Nominalization as racialization in the Italian press? 
o destino inevitável de seu percurso migratório, independentemente do fato de haver cometido crimes ou de sua efetiva periculosidade social"13.

\section{Os centros de detenção como espaços de exceção}

A principal alteração na política migratória deste período e que basicamente pauta as alterações subsequentes foi a adoção da lei Turco-Napolitano, de 1998, que estabelece os Centros de Permanência Temporária para o confinamento dos imigrantes irregulares que não podem ser imediatamente expulsos, mediante o dispositivo da detenção administrativa ${ }^{14}$. Esse dispositivo penaliza o ingresso irregular ou a irregularidade da permanência no país, ou seja, trata-se da infração de uma regra administrativa e não a violação de uma norma penal, que pressupõe um processo legal e uma sentença correspondente. A lei TurcoNapolitano cumpriu o papel de transferir a crise política para a "crise migratória" e potencializou a luta contra a imigração clandestina, articulando normas e medidas mais severas de controle dos estrangeiros, entre as quais: a possibilidade das autoridades de segurança pública exigirem, quando acharem necessário e a qualquer momento, informações e comprovantes de renda proveniente de trabalho ou outra fonte legítima que seja considerada suficiente para sustentar a si e a família residente no mesmo local; a exigência da comunicação da mudança eventual de domicílio habitual ao chefe de polícia responsável no prazo de até 15 dias, sob o risco de severas punições; necessidade de que todo cidadão italiano que deseje receber ou abrigar um estrangeiro em sua residência informe por escrito à autoridade de segurança os dados do indivíduo que irá hospedar e os motivos de sua recepção em até no máximo 48 horas antes de seu ingresso na Itália; obrigatoriedade da apresentação, a qualquer momento, do passaporte ou outro documento de identificação e a detenção por até seis meses para aqueles que não apresentarem uma justificativa razoável por não estar portando estes documentos, entre outros.

Uma das características mais notáveis da lei é a adoção da lógica securitária no interior da política migratória. Todos as medidas acima elencadas reforçam a visão da migração como gestão dos riscos potenciais, independentemente da sua natureza objetiva ou da relevância concreta das supostas ameaças. A lei Turco-Napolitano

13 Ibidem, p. 32. Tradução nossa.

${ }^{14}$ A expulsão dos estrangeiros do território deve ser efetuada nos seguintes casos: por motivo de ordem pública ou de segurança nacional; para os estrangeiros que não passam pelo controle de fronteiras; para os estrangeiros que não possuam visto de entrada e permanência ou nos casos em que a permissão é anulada, não-renovada ou cancelada; para os estrangeiros que representem perigo para a segurança pública de acordo com os parâmetros estabelecidos pelas normas vigentes e como medida de prevenção; como medida de segurança ou como penalidade alternativa à detenção (nos casos em que o estrangeiro tenha sido condenado por um delito cuja pena seja inferior a dois anos ou caso o estrangeiro seja clandestino). 
é fortemente pautada pela discriminação e pela adoção de uma severa vigilância com relação aos estrangeiros, uma vez que aplica procedimentos específicos, uma espécie de "direito especial" para esta categoria de pessoas, independentemente de seu status jurídico. A política pautada pelo arbítrio e pelo medo implica não apenas que as autoridades mantenham uma postura de desconfiança perante os imigrantes, mas também que estes sintam que estão sendo constantemente vigiados, monitorados, e que, no limite, sintam que sua presença é indesejável.

A Lei Turco-Napolitano postula a necessidade econômica como fundamental para estabelecer o padrão do fluxo do ingresso de estrangeiros e aprofunda este entendimento. A lei prevê que a permissão de residência por motivo laboral deva ser concedida apenas durante o tempo em que durar o contrato de trabalho, condicionando a estadia no país de acordo com o interesse dos empregadores, de modo que ao final do contrato, o trabalhador estrangeiro deve retornar ao país de origem. De acordo com Alessandro Dal Lago, a condição dos trabalhadores estrangeiros é de dupla subordinação, social e jurídica, de modo que tais indivíduos são considerados ilegítimos em uma sociedade que não lhes reconhece a existência:

Subordinando a possibilidade de migrar a um contrato de trabalho, obviamente temporário, a nova proposta vincula a inteira existência do migrante, ou melhor, sua possibilidade de existir, à vontade arbitrária dos empregadores. A perda do contrato, além da possibilidade puramente teórica da inclusão em uma lista de colocação, significa a probabilidade concreta da expulsão ou do confinamento em um centro de detenção ${ }^{15}$.

Ao colocar as exigências da economia nacional em primeiro plano, em detrimento das exigências humanitárias, os trabalhadores estrangeiros são concebidos como meros portadores de força de trabalho e não como indivíduos titulares de direitos. Para a antropóloga Annamaria Rivera, a prática da restrição da imigração por meio de normas que consideram o imigrante como simples mercadoria-trabalho reforça o racismo cultural e institucional, reproduzindo um mecanismo de discriminação e violência, de modo que tais normas

alimentam o processo de clandestinidade, limitando o direito de asilo e os reagrupamentos familiares, militarizando a estratégia de confronto com os ingressos regulares, reservando somente aos não-comunitários medidas como as de 'controle digital', multiplicando os centros de detenção administrativos, tornando rotineira a prática da expulsão coletiva, além das representações negativas, sobretudo a ideia já corriqueira de uma presença abusiva e ameaçadora ${ }^{16}$.

Independentemente do motivo da expulsão, ela é acompanhada da proibição do reingresso na Itália por um período mínimo de cinco anos, e no

${ }^{15}$ DAL LAGO, Alessandro. Il colore del lavoro.

${ }^{16}$ RIVERA, Annamaria. Estranei e nemici. 
caso de não observância dessa disposição, o estrangeiro é punido com a reclusão de dois a seis meses. No caso de impossibilidade de efetuar a expulsão imediata, o estrangeiro deverá ficar confinado em um dos Centros de Permanência Temporária até que os procedimentos para a expulsão sejam definidos e praticados. Deve-se observar que, embora a nomenclatura oficial destes centros remeta à configuração de espaços de acolhimento temporário, eles funcionam de fato como centros de detenção, nos quais os imigrantes, potenciais refugiados e solicitantes de asilo são mantidos em confinamento até que seja concretizada sua expulsãoldeportação. Nos relatórios efetuados por Organizações internacionais não governamentais, tais como Anistia Internacional, Global Detention Project, Human Rights Watch, Médicos sem Fronteiras, Migreurop e Médicos para os Direitos Humanos, bem como em documentos realizados por instâncias da União Europeia, como o efetuado pelo comissário para os direitos humanos do conselho Europeu ${ }^{17}$, há uma ênfase bastante clara na definição destes espaços como centros de detenção, sobretudo após tais instituições efetuarem visitas in loco ${ }^{18}$. Para Annamaria Rivera, a história destes centros é também a história de uma relação de poder mediada pela linguagem, que, ao mascarar sua função por meio do recurso ao eufemismo, à figuras retóricas que alteram seu sentido, permitem atenuar seu significado e naturalizar a exceção como regra ${ }^{19}$.

É importante, portanto, destacar, que a edificação dos Centros de Permanência Temporária, hoje denominados, sem o uso de qualquer eufemismo, de Centros de Identificação e Expulsão, foi um instrumento importante no interior da consolidação do Estado de emergência. A partir das alterações afirmadas pela lei Bossi-Fini ${ }^{20}$, de 2002, que não apenas altera o nome dos centros, aproximando os termos daquilo que de fato tais espaços são, como estabelece, principalmente, o crime da "imigração clandestina", foi possível ampliar, "legalmente", o período

17 Cf. Report by Thomas Hammarberg, Comissioner for Human Rights of the council of Europe, following his visit to Italy on 13-15 january 2009.

${ }^{18}$ Cf. ANISTIA INTERNACIONAL. Italy: temporary stay, permanent rights, 2005; HUMAN RIGHTS WATCH. Rights on the line. Human Rights Watch work on abuses against migrants in 2010; Everyday intolerance. Racist and xenophobic violence in Italy, 2011; Relatório mundial 2014-events of 2013 ("immigration detention system"); MÉDICOS PARA OS DIREITOS HUMANOS. Arcipielago CIE. Indagine sui centro di identificazione ed espulsione italiani, 2013; MÉDICOS SEM FRONTEIRAS. Rapporto sui centri di permanenza temporanea e assistenza, 2004; Al di là del muro. Viaggio nei centri per migranti in Italia, 2010; MIGREUROP. Aux bords de l'Europe. L'externalisation des controles migratoires, 2010-2011; Encierro de migrantes. El 'modo de gestión' privilegiado de las migraciones, 2013; GLOBAL DETENTION PROJECT. The privatization of immigrant detention: towards a global view, 2009.

19 "Cpt: una storia semantica". Il Manifesto, 09 luglio 2005.

${ }^{20}$ Para uma interpretação mais detalhada da lei Bossi-Fini, ver: PALEOLOGO, Fulvio Vassalo. Centri di detenzione e ideologia securitaria. In Bada alla Bossi-Fini: Contenuti, 'cultura' e demagogia della nuova legge sull'immigrazione. Roma: Altreconomia, ASGI, ICS, Lo straniero, Lunaria, Terre di mezzo, 2002; GARCIA, op. cit. 
de confinamento nos centros, além de definir um aumento orçamentário bastante significativo para a construção de CIEs, consolidando tais espaços como respostas "excepcionalmente regulares" ao fenômeno da imigração. Nesse sentido, ainda que não tenha havido de fato a suspensão do ordenamento jurídico, o Estado italiano, assim como outras democracias modernas, estabeleceu poderes extraordinários por meio de leis ordinárias, mesmo sem o recurso formal da declaração do estado de exceção. O processo através do qual o fenômeno da migração passou a ser compreendido por meio da ótica securitária evidencia a existência de um determinado regime da emergência que impõe que ocorram alterações permanentes na estrutura jurídica, em uma elaboração constante de normas e exceções que erodem cotidianamente todo o arcabouço jurídicopolítico, seja na ausência da declaração oficial da exceção, seja a partir de sua declaração constante.

Nos "Centros de Identificação e Expulsão", isto é, nos centros de detenção para estrangeiros em situação irregular, efetua-se a espoliação do estatuto jurídico do sujeito, afirmando-se a exclusão da cidadania de determinada categoria de pessoas e mudando o sentido da lei na sua forma, momento no qual o direito deixa de ter o caráter universal e igualitário que o caracteriza para tornar-se um direito especial, exclusivo apenas para determinadas parcelas da população. Tanto nos documentos efetuados pelas organizações internacionais acima citadas, quanto naqueles elaborados por instituições italianas ${ }^{21}$, é unânime a afirmação destes centros como espaços de confinamento ilegais, nos quais pode-se observar: detenção ilegal de pessoas com visto de permanência; presença de mulheres grávidas e crianças junto às demais categorias (homens, criminosos comuns); ausência de separação no interior dos centros entre imigrantes em situação irregular e estrangeiros transferidos em função de crimes cometidos; infra-estrutura inadequada; exposição a temperaturas extremas; superlotação; ausência de espaços internos e externos para recreação (em alguns centros verificou-se que os detidos foram mantidos confinados no interior na maior parte do tempo, com acesso bastante limitado ao ar livre); sujeira, péssimas condições de higiene; ausência de produtos de higiene pessoal, de vestimentas e roupas de cama adequadas e limpas; problemas com oferecimento da alimentação; abusos racistas, agressões físicas, uso excessivo da força por agentes de segurança; uso abusivo de sedativos; inadequação ou ausência de atendimento médico; falta de comunicação sobre os procedimentos legais para expulsão ou para contestá-la; atos de auto-mutilação, tentativas de suicídio em função da extrema frustração, incerteza e ansiedade sobre seu futuro (e falta de apoio|tratamento psicológico adequado para estes casos); relata-se com frequência que, em várias

${ }^{21}$ Especialmente Lunaria, Associazione per gli studi giuridici sull'immigrazione. 
ocasiões, as decisões e encaminhamentos sobre os pedidos de asilo têm sido tomados com base na nacionalidade ou presumível nacionalidade, culminando na ausência do exame individual dos pedidos de acordo com os padrões internacionais estabelecidos e na posterior expulsão coletiva em violação das normas internacionais de proteção dos refugiados e solicitantes de asilo; mortes.

Hegel afirmou, em Princípios da Filosofia do Direito, que "é o imperativo do direito: sê uma pessoa e respeita os outros como pessoas" 22 , princípio que trazia em si a percepção e o entendimento do ser humano como fim em si mesmo, como subjetividade que não poderia ser tutelada ou controlada por qualquer dispositivo externo, pressupondo o imperativo da impossibilidade de que nenhuma força, individual ou estatal, pudesse instrumentalizá-la. O conceito de pessoa - princípio fundamental da modernidade - além de conter em si a essência do direito positivo, expressa também um movimento extremamente significativo pelo qual o indivíduo passava a ter consciência de si enquanto ser de direitos pelo fato de ser humano. O sentido principal da equação hegeliana consistia, portanto, em demonstrar que a particularidade só poderia desenvolver-se plenamente no interior da universalidade, no interior das relações pautadas pela garantia dos direitos, uma vez que estabelecia o imperativo jurídico e político de respeitar a pessoalidade nos outros.

Não obstante esse princípio fundamental, nos Centros de Identificação e Expulsão, o indivíduo confinado não se configura mais como um ser de direitos, sujeito ou pessoa: estes qualificativos lhes são retirados pelo poder soberano. No interior destes espaços de exceção, assim como em outros espaços concentracionários que marcam nosso passado recente, os indivíduos são mantidos em termos puramente vitais, de manutenção da existência, sem a possibilidade de manifestar sua subjetividade, sua identidade, de modo que o tempo e os espaços possíveis de manutenção da sociabilidade são destruídos. Efetua-se, portanto, a alienação total da subjetividade, permitindo o exercício pleno do poder sobre o outro, considerando-o pura e objetiva vida nua:

Pode-se dizer que agredir o homem através da pessoa, ou melhor, a pessoa através do homem, corresponde a duas estratégias diversas de desumanização e de espoliação do ser humano. A primeira é aquela ordinária, normal, legal, do controle social nas instituições totais. A segunda é aquela extrema e destrutiva da guerra total, dos campos de concentração, da tortura em larga escala e do extermínio organizado ${ }^{23}$.

A política migratória italiana, e seu alicerce principal constituído pelos centros de identificação e expulsão, rompe o princípio fundamental segundo o

22 HEGEL, Georg W. F. Princípios da filosofia do Direito, p. 50.

${ }^{23}$ DAL LAGO, Non-persone..., op. cit., p. 209. 
qual "todas as pessoas são iguais perante a lei", de modo que delitos da mesma espécie possuem penas distintas de acordo com o sujeito que os comete ${ }^{24}$, um dispositivo que remete, para Giorgio Agamben, à promulgação das leis raciais da primeira metade do século XX, que estabeleciam quem eram os cidadãos de segunda classe e que, em função disso, não teriam sua cidadania garantida por meio da proteção de seus direitos fundamentais. Os estrangeiros confinados nestes espaços não possuem garantias jurídicas através das quais possam recorrer da decisão que estabelece sua detenção ou para questionar o tratamento degradante ao qual são submetidos, o que representa, para o filósofo italiano, a redução destes indivíduos à vida nua e o restabelecimento dos campos de concentração, se considerarmos sobretudo que "o campo é o lugar no qual, enquanto espaço de exceção, não habitam sujeitos jurídicos mas a existência nua" então "neste caso temos um campo" 25 , uma vez que no período em que estes indivíduos permanecem nos centros eles se configuram como "vidas nuas, privadas de qualquer estatuto jurídico", de modo que os centros de detenção para imigrantes representam a construção de espaços como aqueles que outrora também efetuaram a destruição da subjetividade e da humanidade, servindo como espaço de produção constante da não-pessoa.

A gravidade da existência dos Centros de Identificação e Expulsão e do dispositivo da detenção administrativa pode ser evidenciada sobretudo por assemelhar-se significativamente com o processo através do qual medidas jurídicas e dispositivos políticos tornaram possível que categorias inteiras de seres humanos fossem privados de seus direitos e prerrogativas até o ponto em que cometer qualquer ato de violência contra os mesmos não era considerado um crime ou delito passível de condenação, o que ocorreu durante a edificação dos campos de concentração e extermínio nazi-fascistas. A prática da detenção administrativa, efetuada pelo governo italiano e pelos demais governos europeus cujas políticas migratórias convergem para o combate aos imigrantes, refugiados e solicitantes de asilo, retoma a base jurídica que sustentava os lager nazistas, a Schutzhaft, a custódia preventiva. Por meio desse dispositivo, era possível tomar em custódia indivíduos independentemente de qualquer comportamento desviante, mas de acordo com a configuração somática, religiosa ou étnica com o objetivo de evitar um perigo para a segurança do Estado. Na concepção do estrangeiro como problema social e risco a ser combatido, a semelhança com a proposta da segurança nacional é evidente, uma instrumentalização política do fenômeno migratório que se afasta totalmente das exigências da justiça e

\footnotetext{
${ }^{24}$ Entendimento ratificado também pelo Pacto de Segurança, de 2009, que instaura o agravante da clandestinidade, através do qual a pena por qualquer tipo de delito é acrescida em um terço caso o cidadão que o cometa seja um estrangeiro em situação irregular.

${ }^{25}$ AGAMBEN, Giorgio. Nei campi dei senza nome.
} 
da defesa da universalidade dos direitos humanos. Trata-se, sobretudo, de uma forma de construção demagógica de um consenso político rápido e eficaz para a obtenção do poder.

Outro aspecto relevante da política italiana da emergência permanente é a utilização frequente de decretos-lei, através dos quais se estabelecem medidas jurídicas destinadas a excluir os imigrantes da cidadania. Apesar do ordenamento italiano se caracterizar por uma frágil regulamentação do estado de exceção, de modo que a própria constituição só o regulamenta em casos de guerra (nos artigos 11 e 78), a lei 225 de $1992^{26}$ sobre a proteção civil prevê que o governo possa delegar poderes emergenciais a órgãos especiais com o objetivo de superar uma determinada situação de crise. Nesse caso, o Conselho dos Ministros, por meio de seu presidente, pode deliberar sobre o Estado de emergência e determinar sua duração e extensão territorial de acordo com a suposta gravidade e natureza do evento em questão. Por meio desse dispositivo, diversos decretos-lei ${ }^{27}$ foram efetuados desde o início da emergência, na década de 1990, até os dias atuais, sobretudo após os eventos decorrentes da Primavera Árabe, que culminaram, de acordo com os termos governamentais de então, em uma nova "emergência humanitária" ${ }^{28}$ de proporções similares a um novo "êxodo bíblico".

A prática do recurso frequente do estabelecimento de decretos-lei foi também um elemento constantemente empregado durante o período fascista. Tais medidas excepcionais, bem como seu uso rotineiro, causaram forte impacto na sociedade da época, alterando suas configurações jurídicas, políticas e sociais. Como recorda Giorgio Agamben, o partido fascista utilizou tal decreto-lei em 1926 para tornar-se partido-Estado, quando o regime aprovou uma lei que regulamentava expressamente o recurso a tais dispositivos jurídicos:

Sabe-se que a prática da legislação governamental por meio de decretoslei tornou-se, desde então, a regra na Itália. Não só se recorreu aos decretos de urgência nos períodos de crise política, contornando assim o princípio de que os direitos dos cidadãos não poderiam ser limitados senão por meio de leis (...), como também os decretos-lei constituem a tal ponto a forma normal de legislação que puderam ser definidos como 'projetos de lei reforçados por urgência garantida'. Isso significa que o

${ }^{26} \mathrm{O}$ artigo $2^{\circ}$ define os casos de aplicação da lei, incluindo "calamità naturali, catastrofi o altri eventi che, per intensità ed estensione, debbono essere fronteggiati con mezzi e poteri straordinari".

${ }^{27} \mathrm{O}$ decreto-legge, estabelecido pelo artigo 77 da Constituição, deve ser aprovado pelo Conselho dos Ministros e emitido pelo Presidente da República. Pode ser adotado em casos extraordinários de urgência e necessidade e perde sua validade e eficácia se não for convertido em lei pelo Parlamento nos sessenta dias subsequentes à publicação.

${ }^{28}$ Frases repetidas incessantemente pelos membros do governo, em especial pelo então Ministro do Interior, Roberto Maroni, que ocupou o cargo até o ano de 2011. 
princípio democrático da divisão dos poderes está caduco e que o poder executivo absorveu, de fato, ao menos em parte, o poder legislativo ${ }^{29}$.

As medidas excepcionais, outrora adotadas em casos de necessidade comprovada, como as guerras externas e as guerras civis, passaram a ser utilizadas sob inúmeros pretextos, especialmente no combate ao inimigo interno, na guerra contra a imigração irregular. Tais medidas podem hodiernamente ser instauradas sem que sejam revogadas e sem que possuam uma delimitação clara de seu escopo de tempo e ação, tornando-se parte normal do regulamento ordinário, o que revela o alcance da ampliação do poder estatal e limitação progressiva tanto das liberdades individuais fundamentais quanto do próprio direito, uma vez que a prática da legislação por decreto governamental passou não apenas a ser adotada por diversos setores políticos, como passou a ser amplamente aceita no interior da sociedade civil. Nesse sentido, o paradigma da segurança nacional via estado de exceção (ainda que não formalmente declarado) tornou-se uma técnica normal de governo.

\section{Considerações finais}

A violação dos direitos humanos no interior dos Centros de Identificação e Expulsão tem atingido proporções alarmantes. Após a Primavera Árabe e a entrada de refugiados oriundos especialmente da Tunísia ${ }^{30}$, o governo italiano procedeu à ampliação destes espaços de exceção, aumentando seu número em território italiano, estabelecendo centros "temporários", incluindo os naviosprisões onde foram confinados centenas de tunisianos, e terceirizando os campos por meio de acordos com os países africanos, a despeito da sua já comprovada ineficácia em impedir os ingressos irregulares bem como sua incapacidade de efetuar de fato as expulsões esperadas. Os gastos públicos efetuados para a criação e manutenção destes espaços comprovam de modo enfático que a máquina da guerra não é apenas desumana, como extremamente ineficiente, evidenciando as contradições presentes nos discursos governamentais que afirmam reiteradamente a impossibilidade de investimento em programas de integração e acolhimento dos migrantes ${ }^{31}$.

Novamente, a resposta do governo italiano ao ingresso já esperado de refugiados foi a de afastamento, expulsão e deportação destes indivíduos. A campanha contra o novo êxodo bíblico, contra o tsunami humano alimentou novamente o medo e a rejeição contra os estrangeiros, possibilitando que por

\footnotetext{
${ }^{29}$ AGAMBEN, Giorgio. Estado de exceção, p. 12.

${ }^{30}$ Entre janeiro e maio de 2011, 28.000 migrantes ingressaram no litoral italiano, principalmente na ilha de Lampedusa, em decorrência das revoltas árabes e de perseguições políticas.

${ }^{31}$ Cf. NALETTO, Grazia (org.). Costi disumani. La spesa pubblica per il "contrasto dell'immigrazione irregolare".
} 
meio de decretos de urgência, medidas ainda mais restritivas de ingresso e permanência no país fossem estabelecidas ${ }^{32}$.

Em um cenário caracterizado pela política de força total, na qual o Estado possui um poder de intervenção cada vez mais amplo, o estado de exceção deixou de fazer referência a uma situação de perigo iminente para se confundir com a própria normalidade. Nesse sentido, o internamento, o confinamento e, no limite, a execução, não são vistos como procedimentos excepcionais ou marginais, mas como constitutivos do ordenamento jurídico-político, de modo que é preciso compreender a existência destes espaços de exceção hodiernos no interior de um vocabulário que é próprio da modernidade, que produz campos, instituições totais, panópticos, que normaliza a exceção, a desumanização mas que também constitui uma linguagem mais contemporânea dos efeitos do capitalismo tardio, que gera o risco, a insegurança, o medo, a incerteza, a debilidade, a crise do Welfare State, que efetua o controle difuso, a vigilância constante, entre outros.

Embora as formas dos espaços de exceção mudem, tornando-se mais funcionais e eficazes, permanece, contudo, seu trágico conteúdo: a desumanização do outro, a violência, o arbítrio, a punição coletiva, a destruição das garantias jurídicas e a aniquilação do outro. A existência desses espaços e o retorno do racismo no interior das relações sociais e na esfera institucional apontam para o fato de que embora as declarações internacionais de organizações supranacionais como a ONU tenham, desde o final da Segunda Guerra Mundial, colocado os direitos humanos como princípio fundamental a ser respeitado e garantido, a exclusão, o racismo, a xenofobia e demais fenômenos da violência continuam presentes em nossas sociedades, ocupando lugar central em seu interior. Assim, como alertava constantemente Primo Levi, parece cada vez mais evidente que as tragédias passadas não foram suficientemente compreendidas para que os seus elementos constitutivos tenham sido neutralizados ou que tenham deixado de existir, tornando evidente o risco do retorno daquilo "que aconteceu [e que] logo, pode acontecer de novo" ${ }^{\prime 3}$.

32 Entre elas, o decreto-lei que prevê a expulsão imediata dos imigrantes 'irregulares', mesmo os comunitários, por motivo de ordem pública, e a extensão do prazo de detenção nos CIE's para 18 meses.

${ }^{33}$ Os afogados e os sobreviventes, 1990, p. 123-124: "Devemos ser escutados: acima de nossas experiências individuais, fomos coletivamente testemunhas de um evento fundamental e inesperado, fundamental justamente porque inesperado, não previsto por ninguém. Aconteceu contra toda previsão; aconteceu na Europa; incrivelmente, aconteceu que todo um povo civilizado, recém-saído do intenso florescimento cultural de Weimar, seguisse um histrião cuja figura, hoje, leva ao riso; no entanto, Adolf Hitler foi obedecido e incensado até a catástrofe. Aconteceu, logo pode acontecer de novo: este é o ponto principal de tudo quanto temos a dizer". 


\section{Bibliografia}

AGAMBEN, Giorgio. Estado de exceção. São Paulo: Boitempo, 2004. 2002. . Homo sacer: o poder soberano e a vida nua. Belo Horizonte: Ed. UFMG, . Nei campi dei senza nome. Il Manifesto, 03\01\1998.

. O que é um dispositivo? In O que é o contemporâneo e outros ensaios. Santa Catarina: Argos, 2009.

BROCHMAMN, Grete; HAMMAR, Tomas. Planning in the dark: the evolution of Italian Immigration Control. In Mechanisms of immigration control. A comparative analysis of European regulation policies. New York: Oxford, 1999.

DAL LAGO, Alessandro. II colore del lavoro. II Manifesto, 15\05\2002.

. Non-persone. L'esclusione dei migranti in una società global. Milano: Feltrinelli, 2004.

GARCIA, Fernanda Di Flora. Sobre os Centros de Permanência Temporária na Itália e a construção social da não pessoa. Campinas, 2011, 201 pg. Dissertação de mestrado- Instituto de Filosofia e Ciências Humanas, Universidade Estadual de Campinas.

HANRETTY, Chris; HERMANIN, Costanza. Nominalization as racialization in the Italian press? Florence: European University Institute, 2008.

HEGEL, Georg W. F. Princípios da filosofia do Direito. Lisboa: Guimarães Editores, 1986.

LEVI, Primo. Os afogados e os sobreviventes. Rio de Janeiro: Paz e Terra, 1990.

MANERI, Marcelo. I media creano il panico. In Libro bianco sul razzismo in Italia. A cura di Lunaria: Edizione del'asino, 2010.

. Il panico morale come dispositivo di trasformazione dell'insicurezza. Rassegna Italiana di Sociologia, n. 1, 2001.

NALETTO, Grazia (org.). Costi disumani. La spesa pubblica per il "contrasto dell'immigrazione irregolare". Roma: Lunaria, 2013.

RIVERA, Annamaria. Due anni di scena razzista in Italia. Protagonisti e comprimari, vittime e ribelli. In Secondo libro bianco sul razzismo in Italia. A cura di Lunaria. Edizioni dell'Asino, 2011.

. Estranei e nemici. Discriminazione e violenza razzista in Italia. Roma: Ed. Derive-Approdi, 2003. 


\section{Abstract}

The exception is the rule:

\section{the detention centers for immigrants in Italy}

In the early 1990s, in front of the exponential increase of migratory flows, Italy declares state of emergency to deal with the phenomenon, adopting increasingly restrictive laws to enter and remain in the country and building spaces of exception to confine irregular migrants, refugees and asylum seekers. After nearly 20 years, the state of emergency is still in force and detention centers are mushrooming on the events resulting from the Arab Spring. The purpose of this article is to analyze how exceptional measures have become the rule in Italy and the impact of the existence of these spaces of exception for civil coexistence.

Keywords: detention centers for immigrants, State of exception, racism, Italy.

Recebido para publicação em 19/08/2013.

Aceito para publicação em 08/07/2014.

Received for publication on August, 19 ${ }^{\text {th }}, 2013$.

Accepted for publication on July, 08 $8^{\text {th }}, 2014$.

ISSN impresso: 1980-8585

ISSN eletrônico: 2237-9843

http://dx.doi.org/10.1590/1980-85852503880004315 